\title{
Stakeholders and Risks in Liquified Natural Gas Bunkering Projects: The Hidden Link
}

\author{
Evangelos Bellos (D), Georgios Chatzistelios (D), Angeliki Deligianni* and Vrassidas Leopoulos \\ School of Mechanical Engineering, National Technical University of Athens, 15780 Zografos, Attica, Greece; \\ vbel@central.ntua.gr (E.B.); gchatzis@mail.ntua.gr (G.C.); vleo@central.ntua.gr (V.L.) \\ * Correspondence: aggdelig@mail.ntua.gr
}

check for updates

Citation: Bellos, E.; Chatzistelios, G.; Deligianni, A.; Leopoulos, V.

Stakeholders and Risks in Liquified Natural Gas Bunkering Projects: The Hidden Link. Sustainability 2021, 13, 8140. https://doi.org/10.3390/ su13158140

Academic Editor: Christos Kontovas

Received: 17 May 2021

Accepted: 17 July 2021

Published: 21 July 2021

Publisher's Note: MDPI stays neutral with regard to jurisdictional claims in published maps and institutional affiliations.

Copyright: (c) 2021 by the authors. Licensee MDPI, Basel, Switzerland. This article is an open access article distributed under the terms and conditions of the Creative Commons Attribution (CC BY) license (https:/ / creativecommons.org/licenses/by/ $4.0 /)$.

\begin{abstract}
The importance of stakeholders' analysis for the effective management of risks in any business sector has been widely recognized and depicted in International Organization for Standardization (ISO) standards. This kind of analysis is even more necessary in businesses and organizations dealing with significant technological and market changes, such as the provision and usage of Liquefied Natural Gas (LNG) as a marine fuel. In the LNG bunkering industry, several methods have been proposed to support risk management. However, they all suffer from an important drawback: they guide risk management mainly to the identification, analysis, and control of potential accidental events within a health and safety or a technical reliability analysis framework, failing to structure the correlation of risks with the actual actors, i.e., the numerous stakeholders whose decisions may influence directly or indirectly the organization's objectives. This paper presents a method to systematically analyze the role of stakeholders and their ability to pose threats and/or opportunities to an organization. The proposed approach employs the Social Network Analysis (SNA) methodology to model and analyze stakeholder interests, interactions, and relationships that are important to the organization's objectives. The method is applied in a small-scale LNG bunkering project at a Greek port.
\end{abstract}

Keywords: stakeholders' analysis; risk management; social network analysis (SNA); LNG bunkering

\section{Introduction}

The transport sector is one of the world's leading sources of gas emissions, such as sulfur oxide (SOx) emissions, and hence air pollution, which affects both public health and the environment. Shipping, a branch of transport and dominated by heavy fuel oil since the mid-twentieth century, accounts for about $90 \%$ of global SOx emissions and is responsible for significantly damaging air quality. According to this, the International Maritime Organization (IMO) and the European Commission (e.g., Directive 2012/33/EU) have introduced restrictive regulations addressing ship emissions of exhaust gases to the environment. For this reason, there is a need for a reconsideration of maritime fuel choices. Liquefied Natural Gas (LNG) is one of the options, and it has attracted a lot of interest due to low SOx emissions.

The adoption of LNG by the shipping industry requires the establishment of an efficient supply chain, where various parties should act collaboratively. Nevertheless, one of the primary issues is the uncertainty caused by the lack of infrastructure and bunkering facilities. Though this uncertainty has worried the scientific community and engineers intensely, they are mainly focusing on the common usage meaning of risks that are associated with technical failures and accidents, i.e., the potential of things going wrong (or right).

Nowadays, risk management best practices widen the concept of risk and consider it as a strategic and operational construct, especially in business fields and organizations that deal with major transitions in technology and market, such as the provision and use 
of LNG as a marine fuel. Particularly in the sector of LNG bunkering, several methods have been proposed to support risk management and some of them have resulted in international standards or technical specifications. However, they all suffer from a significant drawback: they guide risk management mainly to the identification, analysis, and control of potential accidental events within a health and safety or a technical reliability analysis framework, failing to structure the correlation of risks with the actual actors, i.e., the numerous stakeholders whose decisions may influence directly or indirectly the organization's objectives.

For this reason, it becomes clear that organizations should be capable of creating and maintaining an appropriate risk management framework to effectively communicate and consult with internal and external stakeholders to understand the business environment's dynamics, opportunities, and threats. As a part of it, a thorough analysis of the needs and expectations of relevant stakeholders would be extremely valuable for effectively managing risks and achieving sustainability.

Within this framework, the TRiTON (Risk Management for LNG Bunkering Facilities) research project, co-financed by the European Union and Greek national funds through the Operational Program "Competitiveness, Entrepreneurship, and Innovation", under the call RESEARCH-CREATE-INNOVATE (project code: T1EDK-01727), proposed a method for systematic analysis of stakeholders' status and their potential to create threats and/or opportunities for an organization implementing an LNG bunkering project. The proposed approach utilizes the Social Network Analysis (SNA) technique to model and evaluate the interests, interactions, and relationships of stakeholders that are relevant to the organization's objectives.

The developed methodology has been applied and validated in a small-scale LNG project at a Greek port. This paper presents some of the important findings of this application.

\section{Literature Review}

\subsection{Risks and Stakeholders' Analysis}

In international management systems standards, risk is defined as the "effect of uncertainty on objectives" [1] while "an effect is a deviation from the expected-positive or negative", according to International Organization for Standardization (ISO), standard ISO 31000 paragraph 3.7 .9 note 1. Furthermore, risks are usually expressed in terms of potential events that may have either a negative (threats) or a positive (opportunities) impact on a project or organization's objectives [1].

Individuals or groups of stakeholders who are (or perceive themselves to be) affected by decisions, policies, and/or processes of a project or an organization [1] are likely to make decisions that serve their interests which may conflict or be in line with those of the organization or the project [2,3]. Therefore, they could be the primary cause of risks, and it is vital for the organization to continuously interact with these stakeholders in order to manage risks and make decisions that take into account the diverse needs and expectations of stakeholders $[2,4]$.

Stakeholders must be considered in any phase of the risk management process, i.e., establishing the context, risk assessment (risk identification, risk analysis, risk evaluation), and risk treatment [4]. The level of stakeholders' participation in each of these phases is a strategic decision of the organization.

Orientation of risk management to stakeholders not only includes communication and understanding of their potential to cause risks but also extends to active engagement in designing and implementing risk management plans $[5,6]$. The advantages of engaging stakeholders are numerous, including a common understanding of risks, the development of trust in decision-making and policy development that affect their sustainability, and the establishment of the perception that the organization aligns with their interests, needs, and expectations [4,7].

Stakeholder management has been used to support risk management in various fields, such as construction management $[3,8,9]$, disaster risk management and crisis 
management $[4,10,11]$, project governance theory [12], complex projects [13], and sports events [2] by a significant number of scholars.

More specifically, Mok, Shen, and Yang [14] by using content analysis (coding and analyzing the main identified research themes) examined the application of stakeholders' management in construction projects by focusing on four main areas: interests and influences, management process, analysis methods, and engagement. They ended up that in order to achieve the greatest results in terms of a project; appropriate techniques and effective management abilities to manage stakeholders are required [14]. An exploratory study of Bal, Bryde, Fearon, and Ochieng [9] was conducted about the processes that are being employed by involved parties to guarantee that sustainability-related concerns are adequately addressed in construction projects. They proposed a cyclic and systematic stakeholder engagement process, suggesting that this process is driven by identification, prioritization, and managing activities, in order for stakeholders to achieve a sustainability goal [9]. In complex projects (CP), according to Aaltonent et al., stakeholder salience, as well as stakeholder matrix and position, have limitations on capturing whether stakeholder attributes can be positive or negative towards the project. For this reason, a salience/position matrix was created to assess changes in stakeholder salience and position, classifying stakeholders based on their degree of salience and supportiveness. According to this, they identify that stakeholders might use eight engagement strategies to increase their salience and influence in a CP by obstructing the project's access to resources in different forms or also using the media and protests [13]. Furthermore, in the literature review of Nguyen, Mohamed, and Panuwatwanich [13] for the approaches and tools of stakeholder management in the context of CPs, they proposed that Social Network Analysis emerges as a powerful tool for understanding the dynamics of stakeholder interrelationships, and that this, in combination with stakeholders' analysis, may create a clearer picture of stakeholders in the context of CPs [13]. In the same vein, for project governance, Ding \& Liu [12] taking into consideration that many organizations are involved in a project, and one organization may have many projects, they discussed on the one hand that there is a social network link between project stakeholders and on the other hand that the social network structure influences the stakeholders' behaviors. For this reason, they argued that social relations among stakeholders can be described based on social networks as a methodology, can be analyzed using the social network metrics, and that stakeholder strategies are influenced by the overall and individual characteristics of the stakeholder network. They presented their arguments using an example of a large-scale information system project in China, concluding that an evaluation of the risk based on the project governance structure can be performed by analyzing and studying the network [12].

Leopkey \& Parent [2] applied a method for two Canadian sporting events, using archival material and interviews, in order to identify and assess stakeholders and gather information about the most relevant areas of concern (sectors of risks). In disaster management, continuous communication between stakeholders by focusing on stakeholders' attributes and perceptions is considered extremely important. In that way, processes for identifying stakeholders that can have an effect or be affected by disasters, processes for analyzing stakeholders' expectations and their effects, and processes for developing appropriate disaster mitigation plans for effectively engaging stakeholders can be effective and efficient $[10,11]$. Furthermore, according to Ndlela [4], in crisis management, risk communication with stakeholders is an important part of the risk management process and necessitates various types of communication and information activities (i.e., change the behavior of stakeholders, exchange information, promote decisions, and involve parties) [4].

The goal of stakeholders' analysis in risk management is not only to improve decision making in a specific project or issue but also to understand the risk perceptions of stakeholders and build sustainable relationships on the basis of common understanding and trust [7]. 


\subsection{Stakeholders' Analysis}

Stakeholders' analysis is a set of tools for gathering and analyzing information and data about parties involved and thus gaining a better understanding of their interests, needs, and expectations [15]. Stakeholders' analysis entails considering the characteristics of various entities. From the perspective of an organization, understanding its stakeholders leads to an evaluation of the impact and resources they bring to decision-making and in general its operation [15,16].

The literature review identifies six key steps in conducting stakeholders' analysis, namely:

1. Identification of stakeholders

2. Stakeholder categorization

3. Investigating relationships and interactions between stakeholders

4. Collecting, recording, and analyzing information

5. Prioritization of stakeholders

6. Monitoring and review

To support the implementation of this process, several tools have been proposed. Table 1 below presents the most important of them.

Table 1. Main tools for assisting stakeholders' analysis steps.

\begin{tabular}{|c|c|}
\hline Step & Main Tools \\
\hline Identification of stakeholders & $\begin{array}{l}\text { Determining and analyzing the value chain [17], examining and decoding the } \\
\text { legislative / regulatory framework around the issue under consideration [17], } \\
\text { focus group [18], interviews and snowball sampling [17,18], conducting interviews } \\
\text { with stakeholders in conjunction with structured surveys [17,18], analysis of } \\
\text { beliefs [17], analysis of social media [17], and questionnaires [17]. }\end{array}$ \\
\hline Stakeholder categorization & $\begin{array}{l}\text { Internal and external [19]; external stakeholders can also be classified as financial, } \\
\text { socio-political, technological, and belonging to the local community [20]. }\end{array}$ \\
\hline $\begin{array}{l}\text { Investigating relationships and interactions } \\
\text { between stakeholders }\end{array}$ & $\begin{array}{l}\text { Actor link matrices [18], Social Network Analysis (SNA) [18,21,22], and } \\
\text { knowledge mapping (in conjunction with the SNA) [18]. }\end{array}$ \\
\hline $\begin{array}{l}\text { Collecting, recording and } \\
\text { analysis information }\end{array}$ & $\begin{array}{c}\text { Analysis of power and influence of stakeholders in relation with the objectives of } \\
\text { the organization }[15,16,23] .\end{array}$ \\
\hline Prioritization of stakeholders & $\begin{array}{c}\text { Analytical categorization (power-interest grid [18,20,24] \& problem-frame } \\
\text { stakeholder map [25]) and reconstructive categorization (stakeholder-led } \\
\text { stakeholder categorization \& Q methodology [18]). }\end{array}$ \\
\hline
\end{tabular}

As shown before, Social Network Analysis is a tool for identifying and analyzing the internal mechanism of stakeholder analysis [26]. This is critical in order to understand how influential each stakeholder is within the framework (e.g., project, policy) under consideration [27].

\subsection{Background of Social Network Analysis}

In recent years, the area of Social Network Analysis (SNA) has gained significant popularity. Several fields are in the spotlight, such as the field of economics, management, computer science, natural sciences, and biological sciences [28,29]. By definition, Social Network Analysis, also known as systemic analysis, is a general approach for analyzing social structures based on relational data [28]. Identification of relationships/interactions among social entities/individuals is the basis of Social Network Analysis (SNA) [18].

Essential components of the social network are the "nodes", which represent social entities (individuals, companies, communities, organizational units, etc.) and "links" that represent the connections among entities using an arc/line [27]. A network is characterized not only by its topology (links and nodes) but also by the information or flow dynamics that occur on it. On the one hand, heterogeneity in the weight (importance) of interactions can be crucial in understanding social structures and is required for a comprehensive analysis 
of these networks [30]. On the other hand, the existence of a large number of links of any weight may be just as significant as the total amount of tie weights [30,31].

Rowley was the first researcher who believed that SNA could be a useful tool for examining stakeholder relationships and uncovering knowledge hidden within social systems [26]. Stakeholders are a part of a social whole that is woven together by the most critical aspect of society: their relationships. Individual properties are only secondary in SNA since the relationships between stakeholders take precedence. It should be noted, however, that in order to fully comprehend social phenomena, the individual characteristics of stakeholders, as well as relational ties, are required [28,32].

In this paper, we propose the use of SNA to assess the potential influence of stakeholders (positive or negative) on the design phase of an LNG bunkering facility as well as their ability to create risks for the organization implementing the project. A stakeholder's influence in our model is determined by the extent to which a stakeholder is involved in/influences activities or decisions that are important for the realization of the project's objectives.

\section{Methodology}

\subsection{Methodological Framework}

As part of the development of the risk management framework, our approach is based on the methodological approach of Bellos et al. [33] for conducting a comprehensive analysis of stakeholders, including their needs and expectations.

The suggested approach, as presented in Figure 1, employs tools and processes to model and analyze the characteristics, interests, needs, expectations, and power of stakeholders, in order to support all the elements (processes, framework, and principles) of a risk management system as defined in ISO 31000 international standard.

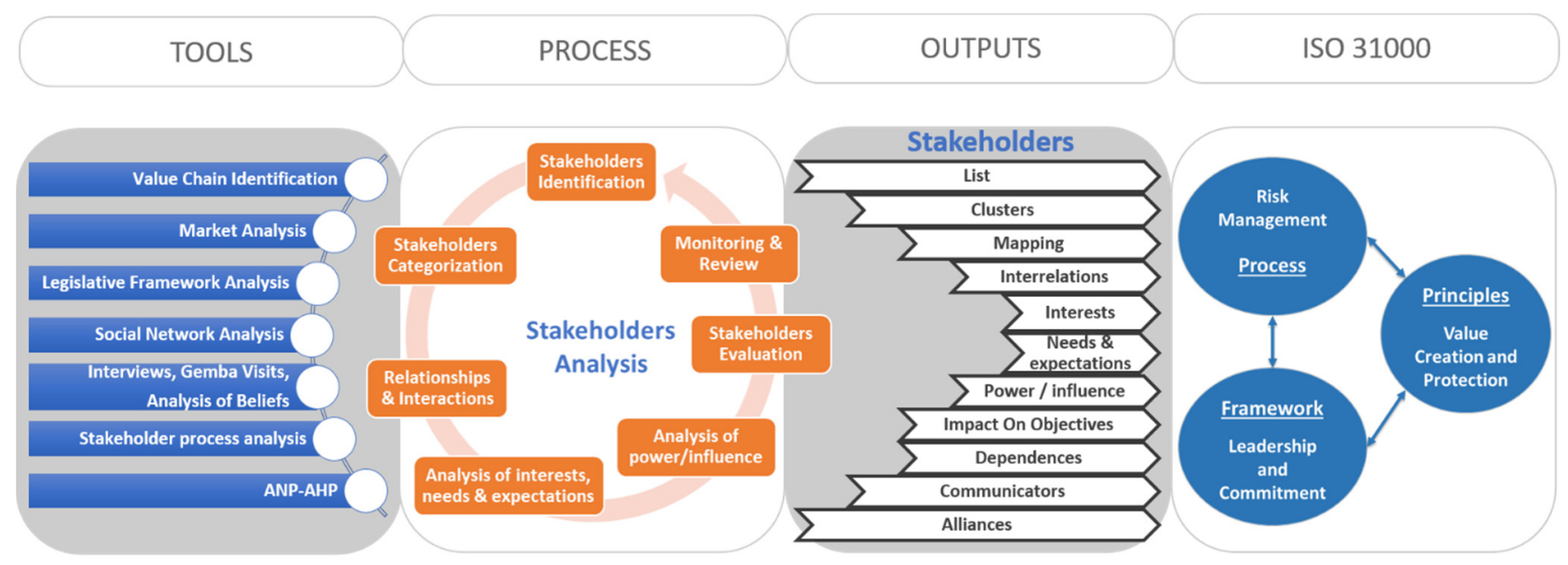

Figure 1. Methodological framework for stakeholders' analysis in risk management.

In this context, a method for developing and analyzing a stakeholders' network with regard to risk is suggested, based on the SNA principles. The proposed methodology consists of the following steps:

1. Identification of stakeholders and interactions

2. Determination of the interactions and relationships between stakeholders

3. Weighting the interactions/relationships between stakeholders

4. Analysis of the stakeholders' network

In the following paragraphs, the practical implementation of the above-mentioned steps are discussed through a case study related to the design of an LNG bunkering facility in detail. 


\subsection{Identification of Stakeholders and Interactions}

The information and tools that can be used for the identification of the main stakeholders and their interrelationships during the design of an LNG bunkering facility are:

- Value chain analysis: Value chain analysis identifies the main stakeholders and interactions that occur on the LNG bunkering value chain, i.e., the supply chain that connects the upstream LNG suppliers with the final consumers at the ports.

- Market analysis: The analysis of both national and international LNG and shipping market allows the identification of stakeholders that may have interest in the operation of LNG bunkering facilities at local ports, as well as the identification of potential constrains related to the use of LNG as a maritime fuel.

- Legislative framework analysis: The analysis of the legislation allows the identification of the entities that are involved in legal activities required by the law for the design and operation of an LNG bunkering facility, such as licensing, safety management, etc.

- Analysis of official information: The analysis of publicly available official information, such as decisions of public authorities related to the project under consideration, strategies, and business plans of the main actors, etc., would allow for capturing the existing dynamics and interests of stakeholders.

- Social media analysis: The analysis of social media (Facebook, Twitter, etc.) enables the collection of informal data about stakeholders and their interactions while at the same time presenting the attitude of each interested party in relation to the project.

Thus, information about stakeholders' attributes and their relationship to an LNG bunkering facility was collected and recorded. An example is presented in Section 4.1.

\subsection{Determination of the Interactions and Relationships between Stakeholders}

During this step, the identified interactions and relationships between stakeholders are characterized according to the interaction types presented in Table 2:

Table 2. Types of stakeholders' interactions/relationships.

\begin{tabular}{|c|c|c|}
\hline \# & Type & Description \\
\hline 1 & Stipulated by the legislation & Correlation provided by the legislation \\
\hline 2 & Customer requirements & \\
\hline 3 & Funding/financial flow & Relationship that indicates intended financing or actual payment of funds \\
\hline 4 & Exercise of authority & $\begin{array}{c}\text { Relationship that implies the exercise of formal authority (e.g., boss-employee or } \\
\text { supervisor-supervisor relationship) }\end{array}$ \\
\hline 5 & Guidelines from standard & \\
\hline 6 & Exercise of influence or pressure & $\begin{array}{l}\text { Relationship that implies the exercise of political pressure, the influence of public } \\
\text { opinion, or the promotion of interests in the context of achieving strategic goals }\end{array}$ \\
\hline 7 & Alliance & $\begin{array}{l}\text { Relationship that suggests the development or formation of alliances between } \\
\text { stakeholders to achieve common goals in relation to the project }\end{array}$ \\
\hline 8 & Cooperation & $\begin{array}{l}\text { Relationship that indicates cooperation for the implementation of technical issues, } \\
\text { operational issues, etc. }\end{array}$ \\
\hline 9 & Material flow & Relationship that indicates the flow of physical material \\
\hline 10 & Competition & Relationship that indicates competition in relation to a project or facility \\
\hline 11 & Information exchange & Relationship that indicates the flow of information \\
\hline
\end{tabular}

\subsection{Weighting the Interactions/Relationships between Stakeholders}

The next step is the assignment of appropriate weight to each interaction between stakeholders so that the relative importance of their impact to the organization's objectives can be depicted, specifically according to the project's time, cost, and quality targets as well as to the organization's values and sustainability.

A qualitative weighting scale was developed as presented in Table 3. A team of experts assisted in the definition of the weighting scale. The qualitative weighting scale of interactions is in line with the recommended Risk Impact Scale for Port Projects by Hashemi et al. [34]. 
Table 3. Qualitative weighting scale of interactions.

\begin{tabular}{cc}
\hline Class & Class Description \\
\hline 1 & Simple interaction between stakeholders, formal stakeholders' relationship, responsibility \\
2 & Interaction with low negative or positive consequence on the project objectives \\
3 & Interaction with low to medium negative or positive consequence on the project objectives \\
4 & Interaction with medium to high negative or positive consequence on the \\
5 & Interaction with high negative or positive consequence on the project objectives \\
\hline
\end{tabular}

The assignment of the weight for each interaction was carried out following the expert judgment approach [35]. A group decision-making process was followed to reach consensus of experts regarding the individual weights [36]. This process consisted of the following steps (step 1 was implemented once at the beginning of the weighting process, while steps 2 to 4 were repetitively implemented for each interaction).

Step 1: The first stage was the formation of the group of experts. Individuals from the partners of the TRiTON project with important expertise in the field formed the group of experts. A lead expert was appointed from the project partner with the highest expertise in the issue under consideration (i.e., design of LNG bunkering facilities). Before the initiation of the discussion, the experts were informed from the lead expert and agreed about the scope of the stakeholder analysis and the weighting process.

Step 2: Conflict stage. During this stage, the experts shared their personal views or thoughts on the weight of the interaction under consideration.

Step 3: Consensus reaching stage. During this stage, the experts sought an agreement on the weight. If full consensus was reached, then the agreed weight value was assigned to the interaction. If not, the next step was followed.

Step 4: The conflict resolution stage. During this stage, a second round of discussion was implemented. If full consensus was not reached again, the lead expert decided on the weight of the interaction, taking into account all the opinions expressed.

\subsection{Analysis of the Stakeholders' Network}

The analysis of the network of stakeholders uses the metrics of social networks, which distinguish the level of influence, trust, and other key properties of the interactions between stakeholders. The stakeholders under investigation are represented by "Nodes", while the relationships between them are represented by "Links" [12,31,32]. It is important to mention here that, in order to understand whether or not and how stakeholders have an effect on an organization's objectives, the links between stakeholders (edges of the diagram) are weighted $[12,31]$ according to the above qualitative weighting scale. The networks that are developed with the use of the Gephi software concern the supply of LNG from an onshore facility, in terms of threats and opportunities. Gephi: The Open Graph Viz Platform is a specialized software tool [37] that allows for the graphical representation of stakeholders and their relationships.

After identifying the stakeholders and their relationships, it is possible to quantify important indices to determine the role of each stakeholder in the network [12].

Centrality is an essential indicator for understanding the relative effect of individual nodes within the network, so it occurs in various expressions of centrality that describe how and to what extent network coherence is organized around specific nodes. The most common centrality expressions that are used to analyze stakeholders' impact are the weighted degree (WD), weighted in-degree (WiD), weighted out-degree (WoD), closeness centrality (CC), betweenness centrality (BC), and eigenvector centrality (EC).

Weighted Degree: The number of weighted connections a node has to other nodes is reflected in its weighted degree [30,31]. Each node's weighted degree is the sum of its weighted in-degree and weighted out-degree. The weighted in-degree value determines how many connections join the node, while the out-degree value determines how many connections exit the node $[30,31]$. The higher the weighted degree value, the more impor- 
tant the role of stakeholder is in the network, and therefore it has greater potential negative or positive impact on the project objectives.

Closeness Centrality: Captures the closeness of one node relative to other nodes in the network [32]. Stakeholders with a high closeness centrality value interact with many stakeholders, whether with a high weighted degree value or not. Demonstrates the ability of a stakeholder to interact directly with other stakeholders and thus directly affect the negative or positive consequences on the project objectives.

Betweenness Centrality: Betweenness is based on finding the shortest paths and counting how many of them pass through a given node [31,32]. The higher the betweenness centrality of a stakeholder, the more often this stakeholder intervenes in the interactions of other stakeholders, and therefore can influence the potentially negative or positive consequences either by inhibiting or intensifying them.

Eigenvector Centrality: This represents a node's indirect influence in a network based on the connectivity of its neighbors [32,38]. Stakeholders with a high eigenvector's centrality value interact with stakeholders that have a high weighted degree (more important role in the network) and have the ability to indirectly (through other neighboring nodes) negatively or positively affect project objectives.

Also, density (DN, Density of the Network) and modularity based on Louvain Algorithm [39] (MN, Modularity of the Network) metrics are used for the analysis of the overall network.

Density: The ratio of the total number of existing links to the total number of possible links (Equation (1)) [12]. The number of potential connections is calculated by the Equation (2).

Density $=$ (number of Actual Connections) / (number of Potential Connections)

Number of Potential Connections $=\{$ number of nodes* $($ number of nodes -1$)\} / 2$

Alliances Modularity: An alliance is a subset of a network in which nodes are more closely and strongly related to one another than to other nodes of the network [32]. The modularity measurement enables stakeholders' groups and future partnerships to be identified [12].

As a result, as discussed in the article of Linåker et al. [40], the various expressions of centrality appear to complement one another, and for our methodology approach, can be used together to create an impact profile for each stakeholder (General Profile), as presented below:

GP (General Profile): Demonstrates the relative importance of each stakeholder taking into account all the examined centrality indicators.

$$
\mathrm{GP}=(\mathrm{WD} / \mathrm{WD}(\max )+\mathrm{CC} / \mathrm{CC}(\max )+\mathrm{BC} / \mathrm{BC}(\max )+\mathrm{EC} / \mathrm{EC}(\max )) / 4
$$

where the indication $(\max )$ refers to the maximum value of the relative indicator that the analysis of the stakeholders' network has.

Stakeholders with a high GP value are expected to be directly or indirectly related with decisions or activities that may have an important impact during the design phase of the LNG facility. This index will provide a more general picture of the relative importance of stakeholders with regards to their influence. A better understanding about the nature of their potential influence on the project can be achieved through the examination of the individual centrality indicators.

\section{Application to a Case Study}

In this section, the proposed methodology is applied to describe and analyze the interactions between stakeholders during the design phase of an LNG bunkering installation. This approach is a result of the TRiTON (Risk Management for LNG Bunkering Facilities) research project, whose coordinator has extensive experience in shipping, and 
in which several contacts have been made with various stakeholders for the validation of application's results.

Liquefied Natural Gas (LNG) is delivered to Greece from upstream suppliers and temporarily stored at the Revithusa's LNG import terminal, which is run by DESFA S.A., the Hellenic Gas Transmission System Operator. LNG ships can be fueled using one of three alternative supply options: LNG bunker ships, LNG trucks, or onshore installations. Onshore installations can be supplied in one of two ways: LNG bunker ships or LNG trucks. In a case study on an onshore LNG bunkering facility, we demonstrate how SNA can be used and how useful it is.

\subsection{Identification of Stakeholders}

Based on the analysis of the legislative framework, the value chain, the LNG market, and the information from the internet, 34 stakeholders were identified and were grouped into two groups: institutional and non-institutional stakeholders.

The institutional stakeholders (\#22 and 65\% of all stakeholders) were: Commission for determining the boundaries of the seashore, European Commission, Fire Service, General Chemical State Laboratory, Government, Greek State, Hellenic Gas Operator, Ministry of Citizen Protection, Ministry of Culture and Sports, Ministry of Development \& Investments, Ministry of Environment and Energy, Ministry of Finance, Ministry of Health, Ministry of Infrastructure and Transport, Ministry of Labor and Social Affairs, Ministry of Maritime Affairs \& Insular Policy, Ministry of National Defense, Municipality, Opposition Political Parties, Port Authority, Local Authority (Prefecture), Regulatory Authority for Energy.

Non-institutional stakeholders (\#12 and 35\% of all stakeholders) were: Banks, Citizens, Citizens' protest groups, Engineer, Environmental organizations, Interested audience, Investors, LNG Suppliers, Media, Organization implementing the project, Other Neighborhood Facility, University Community.

As discussed in Section 3.2, during the identification, information about the attributes of stakeholders and their relationship to project was recorded. Table 4 presents an example of completing the table of stakeholder attributes.

Table 4. Stakeholder attributes table-an example.

\begin{tabular}{cc}
\hline Attributes & Stakeholder Attributes \\
\hline Label & Hellenic Gas Operator \\
Stakeholder Role & Natural gas transmission system operator in Greece \\
Business Sector & Gas \\
Year of commencement of activity in the sector & 2007 \\
Type of stakeholder & Public \\
Organization Size & Large \\
Contact Person & xxx \\
Interest in similar projects & High \\
Legal Decision Authority & No \\
\hline
\end{tabular}

Table 5 presents an example of completing the table with data about stakeholders and their relation to the project. 
Table 5. Stakeholders' relation to project-an example.

\begin{tabular}{cc}
\hline Data & Stakeholder-Project \\
\hline Label & Hellenic Gas Operator \\
\hline Project & \\
Reason chosen/relation to policy & $\begin{array}{c}\text { Strategically expanding its activities to Small Scale LNG projects } \\
\text { through small bunkering ships and tankers } \\
\text { Interest }\end{array}$ \\
Estimated power & $\begin{array}{c}\text { High } \\
\text { Legitimacy } \\
\text { Urgency }\end{array}$ \\
Yes & No participate or engage in the project \\
Level of knowledge about the issue & 3 \\
Estimated Level of support for the issue & Actively supportive \\
Reason for resistance or support & Contributor to the security of supply \\
Consult, Involve, Collaborate
\end{tabular}

\subsection{Determination of the Interactions and Relationships between Stakeholders}

At this step, a detailed analysis of the value chain and the relevant legislative framework was conducted to determine relationships and interactions between stakeholders. Furthermore, extensive research was conducted on social media and other online channels to support the identification of existing informal relationships between the parties involved.

The analysis presents that the overall number of identified relationships was 177 and the number of interactions was 323. It is important to mention here that a relationship between two stakeholders can consist of many interactions. Table 6 demonstrates the number of identified interactions per type of relationship.

Table 6. Basic identified interactions.

\begin{tabular}{ccc}
\hline Type & Number of Interactions & $(\%)$ \\
\hline Stipulated by the legislation & 156 & $48.3 \%$ \\
Funding/financial flow & 12 & $3.7 \%$ \\
Exercise of authority & 15 & $4.6 \%$ \\
Exercise of influence or pressure & 127 & $39.3 \%$ \\
Alliance & 3 & $0.9 \%$ \\
Cooperation & 1 & $0.3 \%$ \\
Information exchange & 9 & $2.8 \%$ \\
\hline
\end{tabular}

\subsection{Weighting the Interactions/Relationships between Stakeholders}

The definition of the weight of each interaction was achieved following the process described in Section 3.4.

A total of twelve experts participated, representing all the partners of the TRiTON project, namely:

- National Technical University of Athens (NTUA), experienced in risk management and facilities design.

- Ocean Finance, specialized in the shipping and energy sector providing financial planning services, strategic investments, and financial combination tools.

- National Centre for Scientific Research "Demokritos" (NCSRD), experienced in research and technological development in selected areas of Reliability and Security of Complex Technological Systems.

- The Hellenic Organization for Standardization, experienced in the preparation, publication and promotion of the implementation and use of Greek standards and standardization documents.

- Port Authority of Volos, responsible for the improvement and development of the port, the provision of ship berthing, the operation of all types of port infrastructure and the undertaking and execution of relevant programs, studies, and projects. 
The role of the Lead Expert undertook the Scientific Responsible of the TRiTON project, who was a Professor in risk management at NTUA and highly experienced in facilities design.

The assignment of weights to the identified interactions was achieved after 18 twohour meetings.

\subsection{Stakeholders' Network Analysis Results}

By applying the steps in Section 3.5, the results are presented below.

\subsubsection{Analysis of the Threats Network Results}

In the next paragraphs, the basic results of the stakeholders' network analysis in relation to threats are presented.

Density: The network's density is 0.1533 . This means that only $15.33 \%$ of all potential interactions between nodes are presented. The majority of actual interactions are primarily triggered by legislation (65\%).

The examination of individual centrality indicators allows a better understanding of the nature of stakeholders' potential negative influence on the project. The following table (Table 7) presents the three most important stakeholders with regard to each index.

Table 7. Main stakeholders of the threats network.

\begin{tabular}{|c|c|c|c|}
\hline Network Centrality Indices & $\begin{array}{c}\text { 1st } \\
\text { Stakeholder }\end{array}$ & $\begin{array}{c}\text { 2nd } \\
\text { Stakeholder }\end{array}$ & $\begin{array}{c}\text { 3rd } \\
\text { Stakeholder }\end{array}$ \\
\hline Weighted Degree & Ministry of Environment and Energy & Port Authority & Government \\
\hline $\begin{array}{l}\text { Weighted } \\
\text { Out-Degree }\end{array}$ & Ministry of Environment and Energy & Government & $\begin{array}{l}\text { Ministry of Maritime } \\
\text { Affairs \& Insular Policy }\end{array}$ \\
\hline $\begin{array}{l}\text { Weighted } \\
\text { In-Degree }\end{array}$ & Ministry of Environment and Energy & Port Authority & Government \\
\hline Closeness & Government & $\begin{array}{l}\text { Local Authority } \\
\text { (Prefecture) }\end{array}$ & $\begin{array}{c}\text { Ministry of Environment } \\
\text { and Energy }\end{array}$ \\
\hline Betweenness & Ministry of Environment and Energy & Government & Port Authority \\
\hline Eigenvector & Ministry of Environment and Energy & Port Authority & $\begin{array}{l}\text { Local Authority } \\
\text { (Prefecture) }\end{array}$ \\
\hline General Profile & Ministry of Environment and Energy & Port Authority & Government \\
\hline
\end{tabular}

According to the above results, the Ministry of Environment and Energy appears to be the most significant stakeholder of the network in the design phase on an LNG bunkering facility. It may have the greatest negative impact on the objectives of the project, while at the same time it has the ability to affect the stakeholders both directly and indirectly. These findings are considered reasonable taking into account that the specific stakeholder has a primary role in activities related to licensing procedures, safety issues, and political pressure. It can be mentioned that the Ministry of Maritime Affairs \& Insular Policy appears to have a less important role in creating threats for the project mainly because its role in the licensing process is more limited.

Also, the central Government and the Local Authority (Prefecture) are the two stakeholders that interact more intensively with many others, mainly because at this phase of the project important decisions related to the public interests are taken.

Finally, the Port Authority has one of the most central positions in the network due to its involvement in the activities related to licensing, financial support, and safety issues in relation to the LNG bunkering facility, which is a port facility.

The General Profile of each stakeholder was calculated to evaluate its total potential threat impact. Figure 2 presents the stakeholders' network based on their General Profile (GP). The more important stakeholders are presented with bigger nodes and strong relationships between stakeholders with thicker lines. The most significant stakeholders, according to their relative potentiality to pose a negative impact on the project objectives, are the Ministry of Environment and Energy, Port Authority, and Government (Figure 2). 


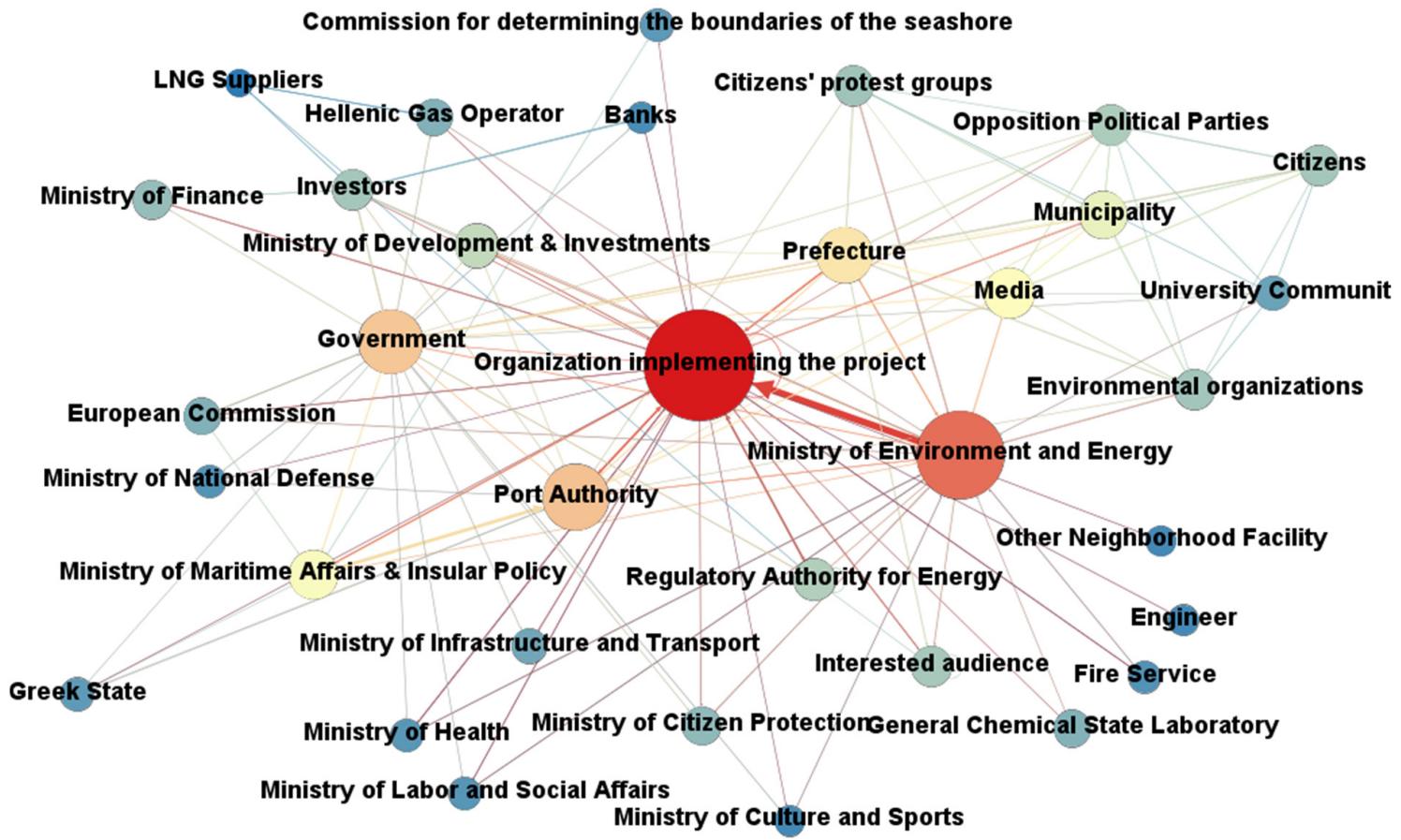

Figure 2. Stakeholders' network for an onshore Liquefied Natural Gas bunkering facility in relation to threats, taking into account the General Profile (GP).

Alliances modularity: The modularity of the network based on the Louvain algorithm is 0.2795 , and according to the same algorithm, the analysis identifies three (3) communities, i.e., groups of stakeholders who might collaborate to control or improve their role in the project. The identified communities are (see Figure 3):

- The construction-related stakeholders (Orange color)

- $\quad$ Stakeholders operating in port management and LNG business sector (Purple color)

- $\quad$ Stakeholders associated with the local community (Green color)

Commission for determining the boundaries of the seashore

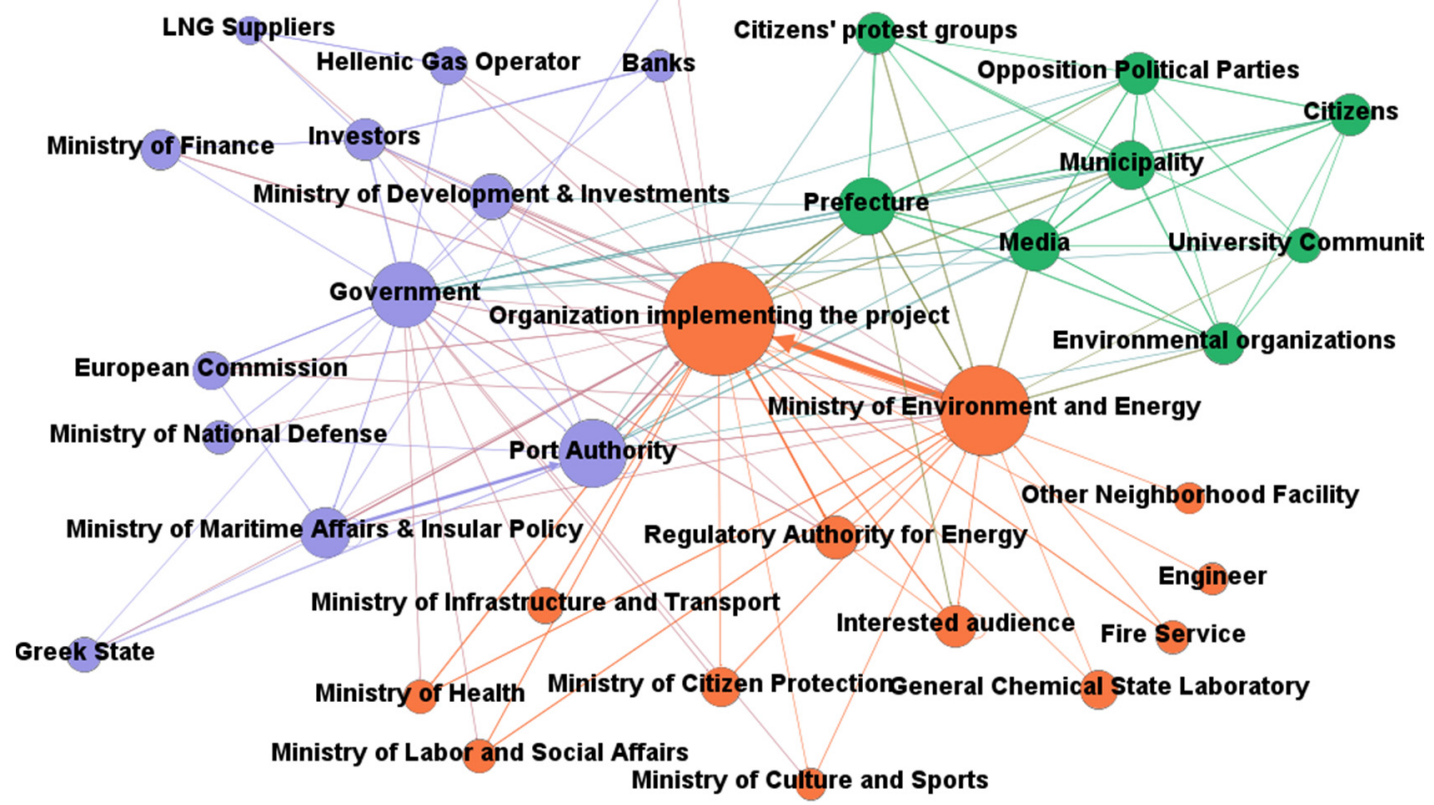

Figure 3. Stakeholders' network presenting the three communities for an onshore Liquefied Natural Gas bunkering facility in relation to threats, taking into account the General Profile (GP). 


\subsubsection{Analysis of the Opportunity Network Results}

In the next paragraphs, the basic results of the Social Network Analysis in relation to opportunities are presented.

Density: The network's density is 0.1468 . This means that the quotient of actual interactions, mainly triggered by legislation $(65 \%)$, to potential interactions between nodes is $14.69 \%$.

Individual centrality indicators are examined to have a better understanding of the nature of stakeholders' potential positive impact on the project. The following table (Table 8) presents the three most important stakeholders with regard to each index.

Table 8. Main Stakeholders of the opportunities network.

\begin{tabular}{|c|c|c|c|}
\hline Network Centrality Metrics & $\begin{array}{c}\text { 1st } \\
\text { Stakeholder }\end{array}$ & $\begin{array}{c}\text { 2nd } \\
\text { Stakeholder }\end{array}$ & $\begin{array}{c}\text { 3rd } \\
\text { Stakeholder }\end{array}$ \\
\hline Weighted Degree & Government & Port Authority & $\begin{array}{l}\text { Ministry of Environment } \\
\text { and Energy }\end{array}$ \\
\hline $\begin{array}{l}\text { Weighted } \\
\text { Out-Degree }\end{array}$ & Government & $\begin{array}{l}\text { Ministry of Maritime Affairs \& } \\
\text { Insular Policy }\end{array}$ & $\begin{array}{c}\text { Ministry of Environment } \\
\text { and Energy }\end{array}$ \\
\hline $\begin{array}{l}\text { Weighted } \\
\text { In-Degree }\end{array}$ & Port Authority & $\begin{array}{l}\text { Ministry of Environment } \\
\text { and Energy }\end{array}$ & Government \\
\hline Closeness & Government & $\begin{array}{l}\text { Local Authority } \\
\text { (Prefecture) }\end{array}$ & Investors \\
\hline Betweenness & Government & $\begin{array}{l}\text { Ministry of Environment } \\
\text { and Energy }\end{array}$ & Port Authority \\
\hline Eigenvector & $\begin{array}{l}\text { Ministry of Environment } \\
\text { and Energy }\end{array}$ & $\begin{array}{l}\text { Local Authority } \\
\text { (Prefecture) }\end{array}$ & Media \\
\hline General Profile & Government & $\begin{array}{l}\text { Ministry of Environment } \\
\text { and Energy }\end{array}$ & Port Authority \\
\hline
\end{tabular}

According to the above results, the Government appears to be the most significant stakeholder of the network. It has the greatest potential to create opportunities for the project, as it can influence many critical decisions and activities, accelerate the permitting process, facilitate financial support of the project (e.g., state funding), reduce bureaucratic obstacles, and motivate potential investors.

The Ministry of Environment and Energy and the Port Authority are the following two most important stakeholders of the network due to their ability to facilitate and accelerate important decisions related to the permitting process and the construction of the project. Moreover, the Port Authority can play a central role in supporting the realization of the investment as part of its strategy for sustainable development.

Also, the Local Authority (Prefecture) has a great potential to influence many other stakeholders and thus facilitate public dialogue and social approval of the investment. Furthermore, it can accelerate many of the activities of the permitting process.

Furthermore, the role of the interested Investors is, as expected, of critical importance for the financial support of the project and the implementation of the investment.

Finally, the Media that are involved in communication activities appear to be able to indirectly influence activities related to social acceptance.

The General Profile of each stakeholder was calculated to evaluate its potential opportunity impact. Figure 4 presents the stakeholders' network based on their General Profile (GP). The most significant stakeholders according to their relative potentiality to pose a positive impact on the project objectives are the Ministry of Environment and Energy, Port Authority, Prefecture, and Media (Figure 4).

Alliances modularity: The modularity of the network is 0.2715 , while the communities remain the same as presented in Figure 3. 


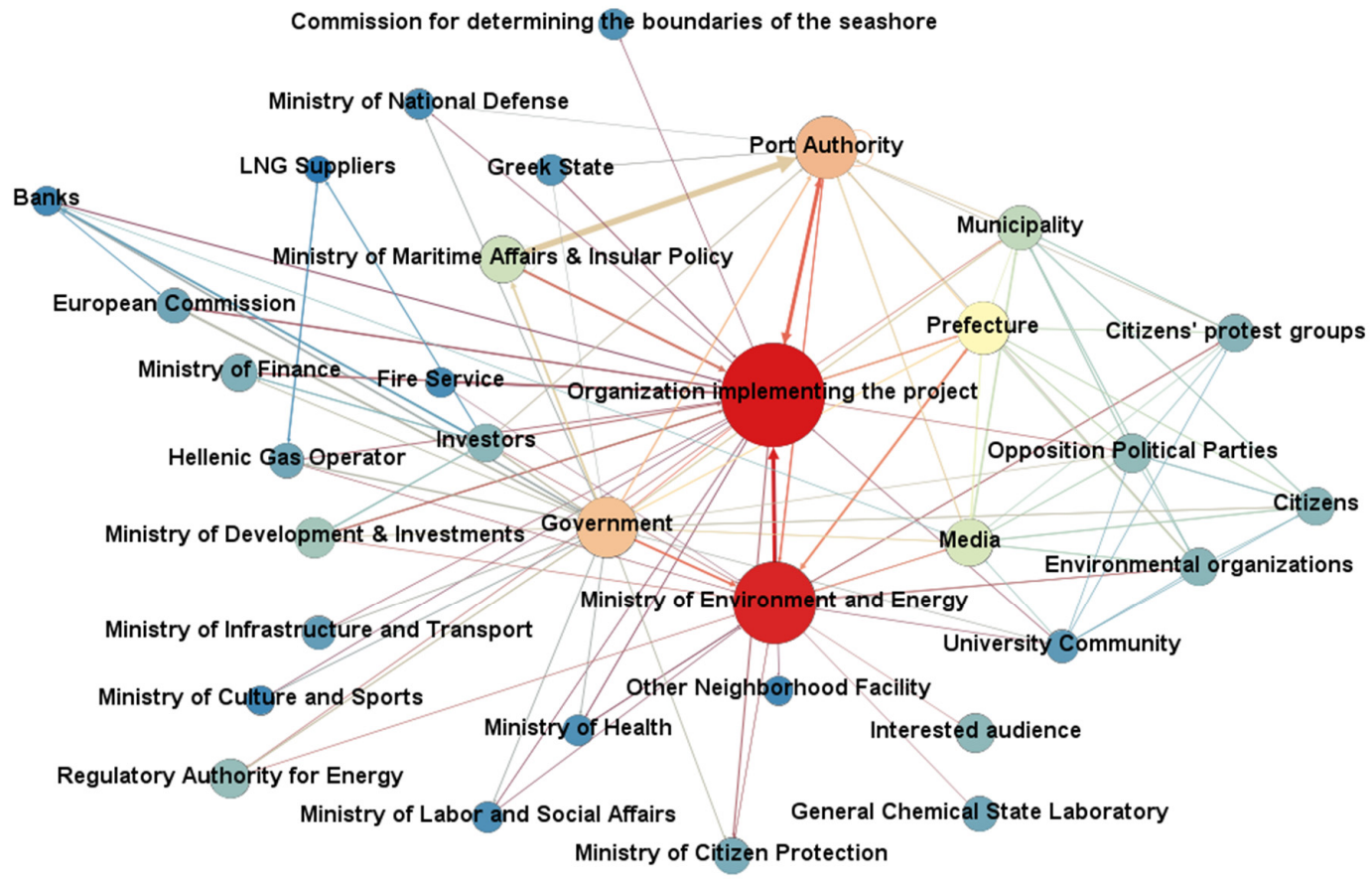

Figure 4. Stakeholders' network for an onshore Liquefied Natural Gas bunkering facility in relation to opportunities, taking into account the General Profile (GP).

\subsubsection{Sensitivity Analysis}

A sensitivity analysis was performed to examine the stability and robustness of the suggested model. The analysis was performed by decreasing and increasing the initial assigned weights by one class, while maintaining the existing weighting scale. The results of the sensitivity analysis showed no significant difference in the ranking of stakeholders in any of the indices used. Figure 5 indicatively demonstrates the results of the sensitivity analysis with regard to the GP index of the opportunity network.

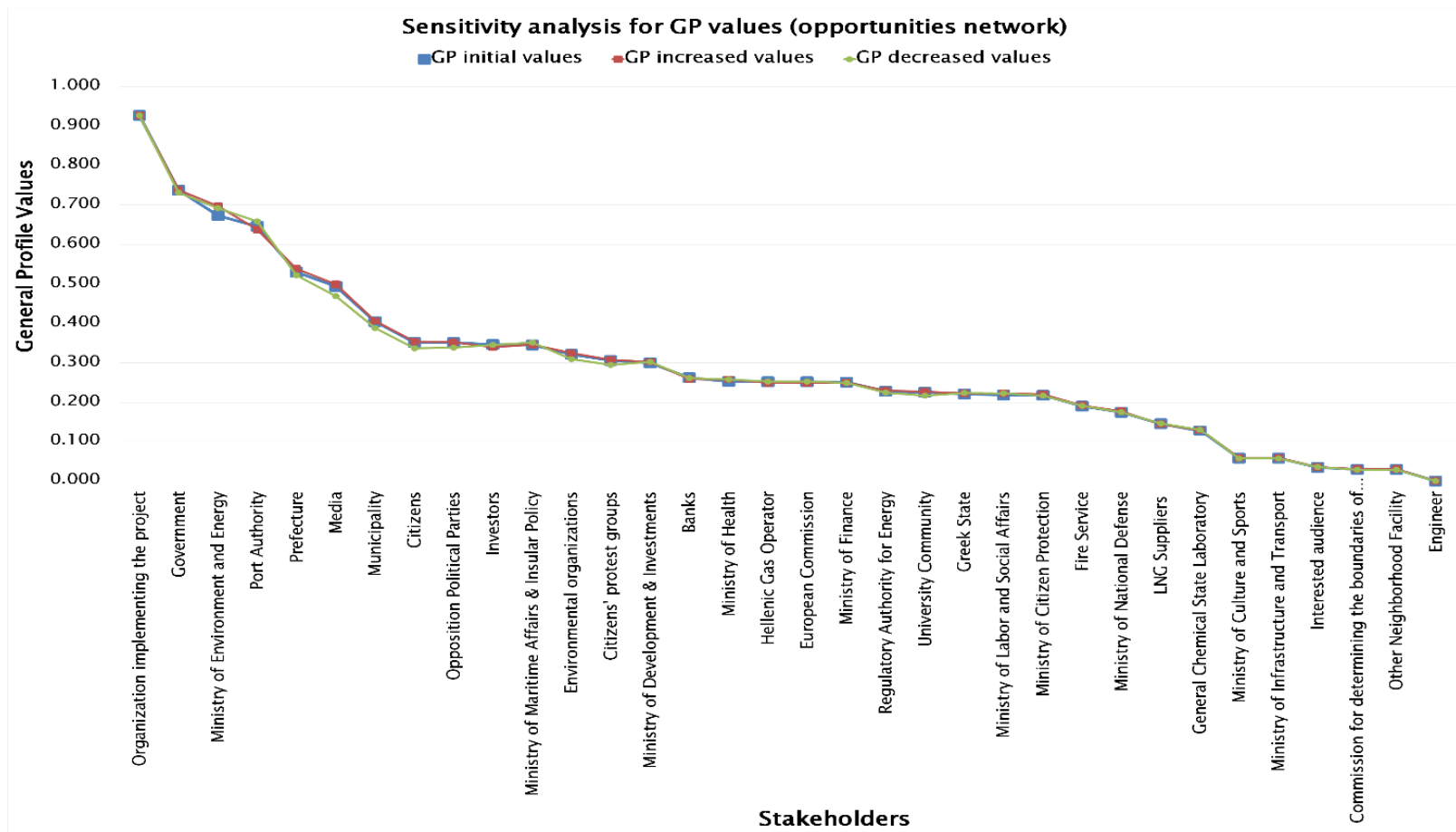

Figure 5. Sensitivity analysis for the opportunities. 


\section{Discussion}

Stakeholders' analysis has been recognized as a valuable method to support risk management in any business sector, especially for organizations dealing with major technological and market changes. In particular, in the field of LNG bunkering, several methods have been proposed to support risk management. However, they mainly focus on the analysis of accidental and failure events and neglect the correlation of risks with their actors, i.e., the project stakeholders.

In this paper, a method to conduct a comprehensive analysis of the importance of stakeholders in relation to risk was proposed by using the principles of Social Network Analysis (SNA).

The value of the present study is considered to be twofold as it contributes to both stakeholder analysis and the scientific field of risk management.

More specifically, the method proposes a more structured approach for identifying and analyzing risk-related information about stakeholders by focusing on key interactions and activities they undertake in support of their interests in relation to a project under consideration. To do this, the method proposes the use of a lot of secondary data from the value chain, regulatory framework, etc., rather than just collecting basic information about them, which is typically not very useful for assessing their power and potential to create risk.

In addition, the method proposes an approach to qualitatively assess the importance of individual stakeholder interactions (e.g., decisions, activities) in relation to risks, thus creating the basis for assessing stakeholder power/importance. This approach is considered an important improvement to the typical direct estimates in Power/Influence Matrices.

Another important contribution of the method is that it allows the assessment of stakeholders' importance in terms of multiple perspectives, e.g., their ability to directly cause risks, their ability to influence other stakeholders and facilitate the creation or control of risks, etc. In this way, the method can be useful for developing an appropriate stakeholders' management strategy.

On the other hand, in the field of risk management, the method practically supports the analysis of stakeholders' needs and expectations as part of the development of the organization's risk management framework, which is a typical requirement of all ISO management standards. This contribution is considered very important as there is no such proposal in ISO risk management standards.

Risk-based stakeholder management is also extremely beneficial for an organization in terms of financial performance and business sustainability. It supports the efficient allocation of resources to deal with risks posed by stakeholders. In this way, the organization can achieve a reduction in the total risk reserves that are held in the organization:

- Contingency Reserve: This is the amount needed to take preventive measures to counter threats and improve opportunities.

- Contingency Reserve Budget: This is the amount that needs to be held to address residual risk (known unknowns).

- Management Slashes Contingency Reserve: This is the amount that needs to be reserved to address threats or enhance opportunities that were not identified during the risk process (unknown unknowns).

It is expected that the proposed method will drastically reduce the risk budget managed by the administration and the security reserve of the project budget with a small increase in the risk management budget.

\section{Conclusions}

The aim of this paper was to present a method for systematically conducting stakeholder analysis to support risk management processes. Using Social Network Analysis (SNA) techniques, the interests, decisions, or activities of stakeholders that may have a significant impact on the organization's objectives were modeled by defining and evaluating the interactions between them. The typical SNA metrics were adapted to provide a 
better understanding of the stakeholders' power or ability to influence and create threats or opportunities for the organization.

The proposed method was applied to analyze stakeholders during the design phase of a small-scale LNG bunkering project at a Greek port within the framework of the TRiTON research project funded by the Greek State. This project involves key organizations with experience in the field of risk management and small-scale LNG facilities.

The method proved its value in identifying stakeholders along with their needs and expectations in a detailed and reasoned manner. It explained the reasons why recognized stakeholders (e.g., the Ministry of Environment and Energy) may create major threats and opportunities for the project, but also revealed the importance of less discussed stakeholders, such as the Local Authorities and the Media, in influencing project objectives. In this way, the proposed method enabled the analysts to obtain a clearer picture of the business environment, helped them better understand the relationship of stakeholders to risks, and created the basis for developing appropriate stakeholder management strategies. Lastly, the analysts involved recognized the ability of the proposed process to practically assist organizations in analyzing their context, as required by the International Management Standards.

The limitation of the method is considered to be the time required to gather information about the stakeholders and analyze the interactions among them. This time can be drastically reduced if the analysts of the organizations reach an appropriate level of experience to quickly focus on the stakeholder activities that can have a great impact on the project. Similarly, the knowledge and experience of the experts involved in the weighting process are critical to the efficiency and effectiveness of the method.

The next research steps will include the consideration of the stochastic dimension of the analysis and the correlation of the identified stakeholders' interactions to the projects' risks.

Author Contributions: Conceptualization, E.B., G.C., A.D. and V.L.; Methodology, E.B., G.C., A.D. and V.L.; Formal Analysis, A.D.; Data Curation, A.D.; Writing-Original Draft Preparation, A.D.; Writing-Review \& Editing, E.B., G.C.; Project Administration, E.B. and G.C.; Funding Acquisition, E.B., G.C. and V.L. All authors have read and agreed to the published version of the manuscript.

Funding: This research has been co-financed by the European Union and Greek national funds through the Operational Program Competitiveness, Entrepreneurship, and Innovation, under the call RESEARCH-CREATE-INNOVATE (project code: T1EDK-01727).

Institutional Review Board Statement: Not applicable.

Informed Consent Statement: Not applicable.

Data Availability Statement: Publicly available datasets were analyzed in this study. This data can be found here: http:/ / triton.simor.ntua.gr.

Acknowledgments: The authors would like to acknowledge the partners of the TRiTON project (i.e., Ocean Finance, National Centre for Scientific Research “Demokritos", Port of Volos, Hellenic Organization for Standardization) for their contribution in this research project. They would also like to thank the anonymous reviewers for the time spent to review this paper.

Conflicts of Interest: The authors declare no conflict of interest. The funders had no role in the design of the study; in the collection, analyses, or interpretation of data; in the writing of the manuscript; or in the decision to publish the results.

\section{References}

1. ISO. ISO 31000-Risk Management-Guidelines; ISO: Geneva, Switzerland, 2018.

2. Leopkey, B.; Parent, M. Risk Management Issues in Large-scale Sporting Events: A Stakeholder Perspective. Eur. Sport Manag. Q. 2009, 9, 187-208. [CrossRef]

3. Chinyio, E.; Akintoye, A.; Barrett, P. Construction Stakeholder Management; John Wiley \& Sons: Oxford, UK, 2009.

4. Ndlela, M.N. Crisis Communication. Crisis Commun. 2019, 1-160. [CrossRef]

5. Fernandes, G.; Domingues, J.; Tereso, A.; Pinto, E. A Stakeholders' Perspective on Risk Management for Collaborative UniversityIndustry R\&D Programs. Procedia Comput. Sci. 2021, 181, 110-118. [CrossRef]

6. Demir, S.T.; Bryde, D.J.; Fearon, D.J.; Ochieng, E.G. Three dimensional stakeholder analysis—3dSA: Adding the risk dimension for stakeholder analysis. Int. J. Proj. Organ. Manag. 2015, 7, 15-30. [CrossRef] 
7. Schwarzkopf, D.L. Stakeholder Perspectives and Business Risk Perception. J. Bus. Ethic 2006, 64, 327-342. [CrossRef]

8. Srinivas, K. Process of Risk Management. Perspect. Risk Assess. Manag. Paradig. 2019. [CrossRef]

9. Bal, M.; Bryde, D.; Fearon, D.; Ochieng, E. Stakeholder Engagement: Achieving Sustainability in the Construction Sector. Sustainability 2013, 5, 695-710. [CrossRef]

10. Mojtahedi, M.; Oo, B.L. Critical attributes for proactive engagement of stakeholders in disaster risk management. Int. J. Disaster Risk Reduct. 2017, 21, 35-43. [CrossRef]

11. Liu, X. The Evolution of Stakeholders' Perceptions of Disaster: A Model of Information Flow. J. Am. Soc. Inf. Sci. Technol. 2013, 64, 1852-1863. [CrossRef]

12. Ding, R.; Liu, F. A Social Network Theory of Stakeholders in China's Project Governance. iBusiness 2011, 3, 114-122. [CrossRef]

13. Nguyen, T.S.; Mohamed, S.; Panuwatwanich, K. School of Engineering and Built Environment at Griffith University Stakeholder Management in Complex Project: Review of Contemporary Literature. J. Eng. Proj. Prod. Manag. 2018, 8, 75-89. [CrossRef]

14. He, Z.; Huang, D.; Zhang, C.; Fang, J. Toward a Stakeholder Perspective on Social Stability Risk of Large Hydraulic Engineering Projects in China: A Social Network Analysis. Sustainability 2018, 10, 1223. [CrossRef]

15. Gilewicz, P.; Cichocka, A.; Frydrych, I. Underwear for Protective Clothing Used by Foundry Worker. Fibres Text. East. Eur. 2016, 24, 96-99. [CrossRef]

16. Brugha, R.; Varvasovszky, Z. Stakeholder analysis: A review. Health Policy Plan. 2000, 15, 239-246. [CrossRef] [PubMed]

17. ISO.ISO 16355_2_Voice_of_Customer; ISO: Geneva, Switzerland, 2017.

18. Reed, M.S.; Graves, A.; Dandy, N.; Posthumus, H.; Hubacek, K.; Morris, J.; Prell, C.; Quinn, C.; Stringer, L. Who's in and why? A typology of stakeholder analysis methods for natural resource management. J. Environ. Manag. 2009, 90, 1933-1949. [CrossRef]

19. Freeman, R.E. Strategic Management: A Stakeholder Approach; Cambridge University Press: New York, NY, USA, 1984; ISBN 9780521151740.

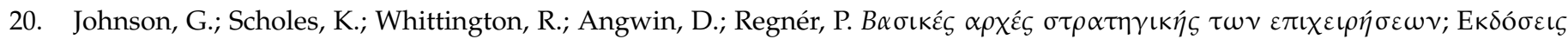
K $\rho \iota \imath \iota \kappa \eta$ : Athens, Greece, 2016; ISBN 9789605861407.

21. Buckingham, K.; Ray, S.; Morales, A.G.; Singh, R.; Martin, D.; Wicaksono, S.; Chrysolite, H.; Minnick, A.; Johnston, L.; Arakwiye, B. Mapping Social Landscapes: A Guide to Identifying the Newtorks, Priorities, and Values of Restoration Actors; World Resources Institute: Washington, DC, USA, 2018.

22. Zedan, S.; Miller, W. Using social network analysis to identify stakeholders' influence on energy efficiency of housing. Int. J. Eng. Bus. Manag. 2017, 9, 1-11. [CrossRef]

23. Prell, C.; Hubacek, K.; Reed, M. Stakeholder Analysis and Social Network Analysis in Natural Resource Management. Soc. Nat. Resour. 2009, 22, 501-518. [CrossRef]

24. Blackman, R. Project Cycle Management- Project Design. In Project Cycle Management; Tearfund Publications: Teddington, UK, 2003; pp. 19-29.

25. Bryson, J.M. What to do when Stakeholders matter. Public Manag. Rev. 2004, 6, 21-53. [CrossRef]

26. Li, H.; Patel, D.; Al-Hussein, M.; Yu, H.; Gül, M. Stakeholder studies and the social networks of NetZero energy homes (NZEHs). Sustain. Cities Soc. 2018, 38, 9-17. [CrossRef]

27. Ludovico, N.; Dessi, F.; Bonaiuto, M. Stakeholders Mapping for Sustainable Biofuels: An Innovative Procedure Based on Computational Text Analysis and Social Network Analysis. Sustainability 2020, 12, 10317. [CrossRef]

28. Otte, E.; Rousseau, R. Social network analysis: A powerful strategy, also for the information sciences. J. Inf. Sci. 2002, 28, 441-453. [CrossRef]

29. Wang, Y.; Wang, S.; Deng, Y. A modified efficiency centrality to identify influential nodes in weighted networks. Pramana 2019, 92, 68. [CrossRef]

30. Barrat, A.; Barthelemy, M.; Pastor-Satorras, R.; Vespignani, A. The architecture of complex weighted networks. Proc. Natl. Acad. Sci. USA 2004, 101, 3747-3752. [CrossRef]

31. Opsahl, T.; Agneessens, F.; Skvoretz, J. Node centrality in weighted networks: Generalizing degree and shortest paths. Soc. Netw. 2010, 32, 245-251. [CrossRef]

32. Hanneman, R.; Riddle, M. Introduction to Social Network Methods; University of California, Riverside: Riverside, CA, USA, 2005.

33. Bellos, E.; Chatzistelios, G.; Deligianni, A.; Leopoulos, V. Stakeholders' Analysis in Lng Bunkering: An Integral Part of Risk Management Process. In Proceedings of the 13th International Conference on Modeling, Optimization and Simulation (MOSIM 2020), Agadir, Morocco, 12-14 November 2020; p. 7.

34. Hashemi, H.; Mousavi, S.M.; Tavakkoli-Moghaddam, R.; Gholipour, Y. Compromise Ranking Approach with Bootstrap Confidence Intervals for Risk Assessment in Port Management Projects. J. Manag. Eng. 2013, 29, 334-344. [CrossRef]

35. Saaty, T.L.; Peniwati, K. The Need for a Structured Approach. In Group Decision Making: Drawing Out and Reconciling Differences, 1st ed.; RWS Publications: Pittsburgh, PA, USA, 2007; p. 385.

36. Pérez, I.; Cabrerizo, F.; Alonso, S.; Dong, Y.; Chiclana, F.; Herrera-Viedma, E. On dynamic consensus processes in group decision making problems. Inf. Sci. 2018, 459, 20-35. [CrossRef]

37. Gephi-The Open Graph Viz Platform. Available online: https://gephi.org/ (accessed on 12 January 2020).

38. Hansen, B.; Derek, L.; Shneiderman, M.; Smith, A.; Himelboim, I. Social network analysis: Measuring, mapping, and modeling collections of connections. In Analyzing Social Media Networks with NodeXL, 2nd ed.; Elsevier Inc.: Burlington, MA, USA, 2020. 
39. Que, X.; Checconi, F.; Petrini, F.; Gunnels, J.A. Scalable Community Detection with the Louvain Algorithm. In Proceedings of the 2015 IEEE International Parallel and Distributed Processing Symposium, Hyderabad, India, 25-29 May 2015; pp. 28-37. [CrossRef]

40. Linåker, J.; Regnell, B.; Damian, D. A method for analyzing stakeholders' influence on an open source software ecosystem's requirements engineering process. Requir. Eng. 2020, 25, 115-130. [CrossRef] 